\title{
Expanding Photonics Education in the International Year of Light
}

\section{Dr. Anca L. Sala, Baker College, Flint}

Dr. Anca L. Sala is Professor and Dean of Engineering and Computer Technology at Baker College of Flint. In addition to her administrative role she is involved with development of new engineering and technology programs and curriculum, improving teaching and assessment of student learning, assessment of program outcomes and objectives, and ABET accreditation. She is a founding member of Mi-Light Michigan Photonics Cluster, and is active in the ASEE, ASME, and OSA professional societies serving in various capacities. 


\title{
Expanding Photonics Education in the International Year of Light
}

\begin{abstract}
The year 2015 has been proclaimed the International Year of Light and Light-Based

Technologies by the United Nations General Assembly ${ }^{1}$. This global initiative will highlight the importance of light and optical technologies in promoting sustainable development and providing solutions to global challenges in energy, education, agriculture and health. Baker College has introduced an exciting, new program in Photonics and Laser Technology in fall 2013 with support from the National Science Foundation Advanced Technological Education (NSF ATE) program. The program is now completing its second year and graduating a first group of well-prepared photonics technicians ready for employment in the growing photonics industry in the state and across the US. The second year marked the successful completion of the program curriculum and further development of the Optics and Photonics Laboratory. Outreach activities included summer programs for high school and middle school students. The paper describes the outcomes of the two year project in relation to the objectives of the NSF ATE grant. Challenges and lessons learned along the way are discussed, together with plans for sustainability and future expansion of the program.
\end{abstract}

\section{Introduction}

Although the term photonics remains largely unknown to the general public, it is now expected that the $21^{\text {st }}$ century will depend as much on photonics as the $20^{\text {th }}$ century depended on electronics ${ }^{1}$. To name just a few, photonics technologies are essential to smartphones, laptops, the Internet, medical devices, lighting and many other applications. Photonics is also used in various manufacturing industries, oil exploration, aviation and aerospace, energy generation and agriculture. Photonics technologies have a major impact on the world economy with a current global market of $\$ 360$ billion, estimated to grow to $\$ 720$ billion by 2020. In recognition of the huge importance of light-based technologies to society and daily life the United Nations General Assembly proclaimed the year 2015 to be the International Year of Light and Light-Based Technologies (IYL). This provides the opportunity to reach and educate people on a global scale about photonics, as well as ensure that international policymakers and stakeholders are made aware of the problem-solving potential of light technology. Throughout 2015 there will be coordinated activities on a national, regional and international level showcasing the central role of photonics in sustainable development. Events taking place in the United States and many other countries can be found on the website of IYL $2015^{1}$.

The Obama Administration has also recognized the strategic importance of photonics technologies in boosting the US economy, creating jobs, and enhancing national security as well as solving other challenges. In October 2014 the Administration announced the creation of an Integrated Photonics Manufacturing Institute, supported by a $\$ 200$ million public and private investment award. The Institute will be led by the Department of Defense and is expected to comprise the largest Federal investment to date ${ }^{2}$. The Institute will bring together companies, universities and other academic and training institutions, and Federal agencies to develop an 'end-to-end photonics ecosystem' in the US. It will serve as a regional hub bridging the gap between applied research and product development and ultimately ensuring that the United States remains a world leader in photonics and light-based technologies. 
A well prepared workforce is vital to the success of the growing photonics industry and the numerous fields where photonics is applied. OP-TEC, one of the National Science Foundation Advanced Technological Education (ATE) Centers, has conducted studies ${ }^{3}$ that show an unmet need particularly for photonics technicians to work in the industry, a need projected to increase in the coming years. Currently there are only about 30 colleges and universities throughout the United States that offer two-year photonics programs ${ }^{4}$, and the number of graduates from these programs is insufficient. OP-TEC is actively working to alleviate this by supporting more colleges to introduce two-year photonics programs. Baker College has started such a program in fall 2013, leveraging a project grant from the National Science Foundation ATE program. Our photonics program is unique in the state. Part of its mission is to raise awareness of photonics as an important advanced technology for the state and the entire country, and of the benefits and rewards of a career in photonics.

\section{The Photonics Education and Training NSF ATE Project at Baker College}

The path from a new program idea to the implementation of the new photonics and laser technology program at Baker College has been described in a paper ${ }^{5}$ given at the 2014 ASEE Annual Conference and Exposition. The present paper describes the evolution of the photonics program and of the NSF ATE project in the second year. Program successes as well as challenges and opportunities are discussed.

The second year activities have continued to focus on the achievement of the five objectives of the grant project. These are: a) create and implement a new Associate of Applied Science Photonics and Laser Technology (AAS PLT) program; b) fully equip an Optics and Photonics Laboratory for education and training; c) train faculty to teach core courses in the AAS PLT program; d) perform outreach activities to local high schools to promote the new program; e) educate 30 or more students or workers by the end of the project.

Objective a) has been fully met by the end of year two in the grant project. The program has now been offered for a full two academic years, and all the program curriculum was developed and taught at least once. The Photonics and Laser Technology program shares foundation courses in electronics with the Electronic Technology program offered at our institution. That can make it attractive to graduates of the latter program who are able to obtain a second major in Photonics in only one additional year. This actually took place at our College where two graduates of the Electronics program signed up for the Photonics major. Due to this circumstance, some of the core Photonics courses had to be developed and deployed ahead of schedule, before the main cohort of students was ready to take them. These courses were pilot tested and adjustments were made where necessary before offering them for the second time.

The other four objectives are in progress and on track to be completed by the end of the grant project at the end of December 2015. Objective b) centers on the Optics and Photonics Laboratory. Laboratory equipment was acquired in stages, to allow for the delivery of the core courses in their respective sequence. Most of the equipment was purchased by the College from its own funds and with help from the NSF grant. The laboratory has also benefitted from generous equipment donations from several companies and from Mi-Light ${ }^{6}$, the Michigan Photonics Cluster. Mi-Light has also supported the new photonics program with student scholarships. 
A major area of focus of the photonics industry in the state are lasers and their applications in manufacturing. The emphasis on lasers is reflected in the program name and in the program curriculum. Lasers are presented in the introductory photonics course, taught in depth in the Laser Fundamentals and Laser Systems courses, and are also heavily featured in the Photonics Applications course. The Optics and Photonics Laboratory supports this emphasis by including several types of lasers: HeNe, carbon dioxide, fiber, diode, Nd:YAG and Argon ion. Test and measurement equipment include detectors, power and energy meters, beam profilers, spectrometers, and high speed oscilloscopes. Miscellaneous optical components, optical breadboards and tables, and various laser safety glasses complete the equipment list. Future acquisitions planned include one or more tunable light sources and an interferometer.

Objective c) refers to training faculty to teach courses in the program. Faculty members have received training primarily through the self-paced online courses offered by OP-TEC. The courses are offered in a flexible format. The lecture portion is conducted online through a classroom management system, followed by hands-on laboratory experiments at the end of the course. This has worked very well for three instructors from Baker College, allowing them to be well prepared to teach the program photonics courses.

Objective d) focuses on outreach activities. The number of outreach activities promoting photonics increased during the second year of the grant. We continued to offer the week-long summer camps to a group of high school students and a group of middle school students in July 2014. The high school group was taught a 3-hour optics and photonics module as part of the "Explore Engineering and Technology" Camp. Nineteen students participated in the high school camp. The middle school camp was titled "Robotics and Photonics". A larger emphasis was placed on photonics this time, with two 3-hour modules of optics and photonics introductory topics taught to participants. Twenty-one students from nine different middle schools participated in the camp. Both high school and middle school modules were conducted in the Optics and Photonics Laboratory and contained numerous hands-on activities. The middle school group particularly enjoyed the activities, with both groups reporting positive experiences in surveys administered at the end of the camps.

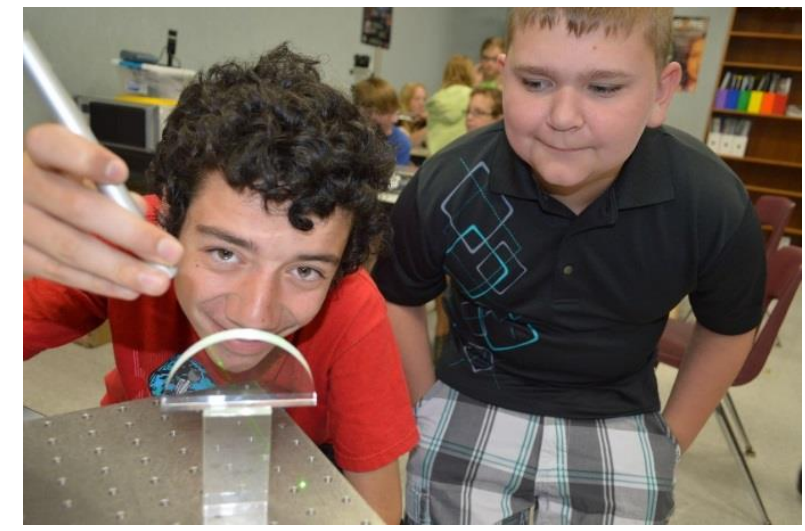

Fig. 1. Experimenting with light in the "Robotics and Photonics" middle school summer camp 2014. 
In addition to the summer camps, several STEM day events took place during the year which included photonics presentations and activities in the lab. The International Year of Light 2015 is an auspicious time to introduce the field of photonics to K-12 students, teachers, counselors, and parents. Participants in STEM day events ranged from elementary to middle school to high school students, accompanied by teachers and counselors. During these events groups of students spent an entire day at the College learning about several engineering and technology fields including photonics through hands-on activities.

The College is also planning an IYL 2015 event to be held on campus to celebrate light and the extraordinary technologies based on it. We hope to attract a wide variety of participants to the event that will be open to the public and is expected to take place in the fall.

Objective e) focuses on the impact of the grant project in terms of the number of students taking courses in the program and the employees trained. The stated goal for objective e) is to have 30 or more students and workers receiving photonics education by the end of the project. Out of the five objectives of the project, objective e) appears to be the most challenging to accomplish. The challenge is two-fold, in recruiting and in retaining students into the program. When the program was new during summer and fall 2013, multiple activities took place to promote and market the program. News releases were published which were carried by national professional magazines such as Photonics Spectra, Laser Focus World and others. The Principal Investigator was interviewed two times on the radio about the field of photonics and the new degree program. All these efforts helped to recruit a first group of students, albeit small. In addition, two graduates from the Electronic Technology program enrolled in the Photonics program as mentioned previously. For the second year of the program it was expected that student enrollment would increase, as the Admissions Department had more time to recruit students and the program became better known. That however did not happen to the extent expected, due to several factors. The student enrollment in the College overall has decreased slightly this academic year, which impacted the photonics program too. In addition, the field of photonics and what kind of jobs are available are still unknown for a majority of people. Educating the public about the field requires a sustained effort. Once again, the IYL 2015 events will help in this respect. We are also expecting that having a group of first graduates from the program who will obtain good employment in the industry will speak about the quality and success of the program and make it attractive to prospective students.

To address the problem of insufficient new student enrollment in the program, the Principal Investigator has recently secured a small grant that allowed the College to hire a dedicated recruiter to attract high school graduates and veterans to the photonics program. This effort will complement the work of the Admissions Department who is the main recruiter of new students. Other colleges that have utilized this approach were successful in increasing the student population in their photonics programs ${ }^{7}$. Also included in the small grant is a pilot project to teach the first introductory photonics course for college credit to a cohort of high school students in fall 2015. The course will be taught in a blended format to accommodate the students' schedules. The theoretical portion of the course will be delivered through Blackboard, with the experimental laboratories taking place at the College. We are targeting 15-20 high school students from several area schools to participate in the pilot course. By exposing high school 
students to the field through this course, we hope to make both the field and the program better known and attract more enrollment.

The second aspect of the challenge with objective e) is the retention of students enrolled in the photonics program. General retention at our College is impacted by it being a "right-to-try" institution. This allows any high school graduate or holder of a GED to enroll in any of our programs. The students who are not well prepared for college work tend to drop after one or two quarters. The College has deployed several initiatives in recent years to help this group get ready for college courses with some success. These initiatives centered on basic mathematics and English courses offered in a cohort format and with extended time allotted for completion of learning outcomes. The photonics program requires good math and science abilities and a handson inclination, in addition to readiness for college work. Even though the drop-out rate from the photonics program has been comparable to the average for the entire College, the goal of the program is to retain all its students as much as possible. This will require careful advising of students and a close relationship with the faculty teaching in the program.

Objective e) also includes training of employed technicians to refresh or expand their photonics knowledge and skills. The Principal Investigator has collected information on topics of interest to employers in order to plan for one or more training sessions to be offered at the College the upcoming summer. Yet another photonics education effort will include offering a workshop to high school science teachers interested in adding an optics and photonics module to their courses. This effort is part of the small grant mentioned above and is targeted for implementation before the end of the current academic year.

Professional development of grant personnel and dissemination of the project results are important components of the NSF ATE grant project. During year two, the grant personnel participated in several conferences including the HI-TEC and ATE PI Conferences. A paper describing the new photonics program was presented at the international society for optics and photonics (SPIE) Optics + Photonics Conference. Though focused mostly on optical sciences and technology research results, the conference included an education track where a variety of photonics educational opportunities were presented, from short one day programs to degree programs offered by colleges and universities.

\section{Conclusions and Future Steps}

The Associate in Photonics and Laser Technology program has successfully completed its second year, marking also the end of the second year in the NSF ATE grant project. The program is now fully implemented including the entire course curriculum and the experimental laboratory equipment. The Advisory Board with industry representation continues to meet two times per year to guide the program and ensure its relevance to current industry needs.

The focus of the project is now shifting towards growing the program and making it sustainable through increased student enrollment and graduation rate. We are also focusing on extending the grant project's impact through reaching multiple groups, including K-12 students from elementary to high school level, science teachers, counselors, veterans and employed technicians. Numerous outreach and educational activities involving these groups have taken place, and others are planned for the near future. Year 2015 which was designated as the 
International Year of Light presents a great opportunity to reach the general public and raise its awareness about the field of photonics and its importance to society.

The Baker College program is open to and interested in sharing its accumulated experience with other colleges considering adding a two-year photonics program. Numerous resources are available to such colleges through the OP-TEC website ${ }^{4}$. The support of other organizations such as NSF, Mi-Light and photonics companies in the state has also been invaluable from the project's inception through the full implementation of the program. We look forward to continued and expanded partnerships with secondary and post-secondary schools and employers, resulting in program growth and ultimately growth of the photonics industry and related fields.

\section{Acknowledgement}

This paper is based upon work supported, in part, by the National Science Foundation Advanced Technological Education program, under Grant DUE \# 1304071.

Any opinions, findings, and conclusions or recommendations expressed in this material are those of the author and do not necessarily reflect the views of the National Science Foundation.

\section{References}

1. 2015 International Year of Light and Light-Based Technologies, http://www.light2015.org/Home.html, accessed on Jan. 3, 2015.

2. Announcement of creation of the Integrated Photonics Manufacturing Institute by the Obama Administration, http://www.prnewswire.com/news-releases/obama-administration-announces-200-million-in-public-privateinvestment-to-create-an-integrated-photonics-manufacturing-institute-278014311.html, accessed on Jan. 3, 2015.

3. "Industry Demand for Two-Year College Graduates in Optics and Photonics Technology, A 2012 Industry Survey of Current and Future Demand for Two-Year Degreed Photonics Technicians", http://www.op-tec.org/2012survey.php, accessed on Jan. 9, 2015.

4. Colleges and universities with photonics education programs, http://www.op-tec.org/OPCN.php, accessed on Jan. $15,2015$.

5. A. L. Sala, "Developing a Photonics and Laser Technician Education and Training Program", 2014 ASEE Annual Conference and Exposition.

6. Mi-Light, Michigan Photonics Cluster, www.mi-light.org, accessed on Jan. 15, 2015.

7. C. Panayiotou, "Infusing Biomedical Applications of Photonics into Electronics Engineering Technology AAS Programs: A Program Planning Guide", OP-TEC, http://www.op-tec.org/pdf/op-tec bio-med_ppg 111312.pdf, accessed on Jan. 15, 2015. 